\title{
Cyberbullying Victimization and Cyberbullying Perpetration with Self-Esteem as the Moderator
}

\author{
Tan Kim Hua, Nicholas Sia Heng Hwa, Sheau Tsuey Chong
}

\begin{abstract}
Cyberbullying is a growing phenomenon with many negative and long-term effects. Past literature has not been consistent in the findings with regard to the relationship between cyberbullying victimization and perpetration. The role of self-esteem in its interaction from both aspects of cyberbullying has also been inconclusive. This study therefore sought to examine the relationship between cyberbullying victimization, cyberbullying perpetration with self-esteem as its moderating factor. 120 participants (aged 18 to 25 years old) were recruited to complete the surveys comprising the Cyberbullying and Online Aggression Survey and the Rosenberg Self-Esteem Scale. Hierarchical multiple regression was run to analyse the predictive relationship of the variables. One finding shows that cyberbullying victimization and cyberbullying perpetration have positive correlation which may explain the propagation of the vicious cycle. The other finding did not seem to highlight the role of self-esteem in mediating the perpetration and victimization of cyberbullying. This study nevertheless provides valuable insights to the nature of cyberbullying which can assist in the management of this pervasive social ill in community programmes.
\end{abstract}

Keywords: cyberbullying, self-esteem, perpetration, victimization

\section{INTRODUCTION}

With the advent of social media and the digitalisation of communication, cyberbullying has inevitably been a growing phenomenon. Despite the various definitions and nature of cyberbullying, the general characteristic researchers have unanimously agreed on is that it takes place in the realm of electronic text [1], [2]. However, for the purpose of this study, one definition will be used where Smith et. al [3] refers cyberbullying as 'an aggressive act or behaviour that is carried out using electronic means by a group or an individual repeatedly and over time against a victim who cannot easily defend him or herself'.

Characteristics of cyberbullying absent in traditional bullying include the degree of anonymity contained in the former where the identity of the perpetrator could be

Revised Manuscript Received on September 25, 2019

Tan Kim Hua, Center of Literacy and Socio-Cultural Transformation, Faculty of Social Sciences and Humanities, Universiti Kebangsaan Malaysia, 43600 Bangi, Malaysia.

Nicholas Sia Heng Hwa, Faculty of Behavioural Sciences, HELP University, 15, Jalan Semantan, Bukit Damansara, 50490 Kuala Lumpur.

Sheau Tsuey Chong, Centre for Youth Empowerment, Faculty of Social Sciences and Humanities, Universiti Kebangsaan Malaysia, 43600 Bangi, Malaysia. masked [4] and the inherent ability of the act to reach a bigger group of people with minimal effort or consequence due to the accessibility of the medium [5]. This may pose added risks to the victim where it further limits actions of retaliation and defence in response to the bullying act.

The psychological and emotional damage caused by cyberbullying could be immense and equal, if not more detrimental than to that of traditional bullying. A survey that asked adolescent victims of cyberbullying found that over $93 \%$ reported feelings of sadness, hopelessness, and powerlessness [6] and also significant psychosocial, affective and academic problems in their day-to-day lives [7]. Moreover, reference [8] also highlighted the fact that exposure to cyberbullying may impact and increase suicidal behaviours among high school students while both cyberbullying victimisation and perpetration were found to be positively correlated with depression [9]. Furthermore, effects of cyberbullying are not just restricted to psychological damage as found in a meta-analysis [10] that both bullies and victims pose a significantly increased risk for psychosomatic issues compared with their peers who are uninvolved in bullying. In addition to the aforementioned, witnesses of cyberbullying could also undergo a process of desensitization engendering lower levels of empathy due to its exposure to the act [11].

With regard to motives, previous studies have found factors such as revenge, boredom, curiosity and jealousy to be driving the cyberbullying phenomenon [12][14].

This study specifically sought to examine the factors of victimisation and perpetration in relation to cyberbullying. Previous literature has maintained a connection between the two thus demonstrating that individuals who are involved in bullying victimization may also be involved in bullying perpetration [15]-[17]. This could also be the reason why the phenomenon of cyberbullying could be a vicious cycle.

Self-esteem relates to how an individual perceives and views himself. Much research has focused on the connection of self-esteem and how it is in conjunction with cyberbullying. As reported by researchers, middle-school students involved in cyberbullying, both as victims and perpetrators, to be linked with significantly low self-esteem ratings [18]. They further contend that the lack of selfesteem may contribute to both cyberbullying victimization and perpetration hence being both the effect and cause of the issue. This continued to be echoed by study [19] where they found loneliness, empathy and self-esteem levels predicted cyberbullying victimization and perpetration. Furthermore, study [20] reported that in addition to low self-esteem levels, high 
narcissism was also deemed to predict both aspects of cyberbullying. However, a study [21] found low self-esteem levels did not produce a predictive factor for cyberbullying victimization and perpetration. Another study which further expounds the complicated relationship between self-esteem and cyberbullying is where they wrote that students with high levels of self-esteem predicted bullying perpetration when being bullied while students with lower self-esteem reported lower probability in bullying perpetration [22]. Therefore, there exist multiple discrepancies on the topic hence necessitating the current study. Based on the aforementioned, studies on cyberbullying have focused mainly on children and adolescents where little has been done to explore other demographics with regard to this subject. This study aims to bridge this gap by using college students as participants. Therefore, this study aims to answer the following questions: is there a relationship between cyberbullying victimization, cyberbullying perpetration and self-esteem. The hypotheses in this study include a) cyberbullying victims are likely to be cyberbullying perpetrators and b) self-esteem weakens the likelihood of people who are cyberbullying victims also being cyberbullying perpetrators.

\section{METHODOLOGY}

\section{Design}

This study utilised a non-experimental correlational design to examine the association between the variables of cyberbullying victimization, cyberbullying perpetration, and self-esteem. Cyberbullying victimization is defined as the degree to which an individual has been cyberbullied while cyberbullying perpetration is the degree to which an individual has been involved in cyberbullying others. Selfesteem is defined as the way people see themselves, whether positive or negative. The predictor variable of cyberbullying victimization and the criterion variable of cyberbullying perpetration was measured by the Cyberbullying and Online Aggression Survey while the moderating variable of self-esteem was measured by the Rosenberg Self-Esteem Scale.

\section{Participants}

120 undergraduate aged 18-25 years students from different faculties from a local University were recruited on the University grounds to participate in the study. There were 69 Malaysian Chinese (57.5\%), 24 Malaysian Malays (20\%), 13 Malaysian Indians (10.8\%), 3 Ibans (2.5\%) and 11 foreigners of nationalities of Brunei, Indonesia, Nepal, South Korea, Bangladesh and China (9.2\%). With regards to gender, there were 45 male and 75 female participants.

\section{Materials}

The Cyberbullying and Online Aggression surveys [18] were used to measure both the predictor variable of cyberbullying victimization and the criterion variable of cyberbullying perpetration. The scale is a multi-sectioned survey where items 1-9 refer to the number of times that they have experienced cyberbullying (the cyber victimization scale), while items $10-18$ refer to the number of times they have perpetrated cyberbullying (the cyber offending scale). A 4-point Likert scale ranging from "Never" (denoted as 1) to "Many times" (denoted as 4) is used for items 1-18. The higher the accumulation of points denotes the higher the involvement in cyberbullying. The victimization scale has a Cronbach's alpha range of $0.867-$ 0.935 while the offending scale has a Cronbach's alpha range of $0.793-0.969$.

The second scale utilised in this study is the Rosenberg Self-Esteem Scale measuring the moderating variable of self-esteem [23]. It is a 10-item scale that measures self-worth by identifying how one feels about oneself, whether positive or negative. A 4-point Likert scale format is used, ranging from "Strongly agree" (denoted as 4) to "Strongly disagree" (denoted as 1). Higher scores indicate higher self-esteem. The Rosenberg self-esteem scale has an internal consistency of 0.88 .

\section{Procedure}

The data was collected via the distribution of questionnaires on the University grounds. Firstly, participants were approached and asked to read and sign a letter of consent, informing them of the terms and conditions of the survey. The participants were then asked to complete the questionnaire, which consisted of 3 sections, namely A: Demographic information, B: Cyberbullying and Online Aggression survey and finally C: Rosenberg's Self-Esteem Scale. This process took approximately 10-15 minutes. Subsequently, participants were thanked for their participation and informed that they could contact the researcher if they had any further questions.

\section{Statistical Analysis}

Hierarchical multiple regressions were used where the relationship between cyberbullying victimisation and perpetration were examined with self-esteem acting as the moderating variable. More importantly, it indicates whether or not the moderator variable of self-esteem truly moderates the relationship between cyberbullying perpetration and cyberbullying victimization.

\section{RESULTS}

Based on the survey, measures of cyberbullying perpetration, victimization and self-esteem were calculated. Table 1 refers to the mean and standard deviation of the variables measured. The predictor variable of cyberbullying victimization reports a mean of $11.42(\mathrm{SD}=$

\begin{tabular}{ll}
\hline Variables & Mean \\
\hline Cyberbullying perpetration & $10.18($ s.d. $=2.37)$ \\
Cyberbullying victimization & $11.42($ s.d. $=3.36)$
\end{tabular}

Cyberbullying victimization 
Self-esteem

$28.22($ s.d. $=4.38)$

Table 1: Mean scores of cyberbullying victimization, cyberbullying perpetration and self-esteem

3.36) while the criterion variable of cyberbullying perpetration reports a mean of $10.18(\mathrm{SD}=2.37)$. The moderator of self-esteem on the other hand, reports a mean of $28.22(\mathrm{SD}=4.38)$.

\section{Correlation Analysis}

A Pearson correlation analysis was conducted to study the relationship between cyberbullying perpetration and cyberbullying victimisation. It was found that a positive significant relationship exists between the two variables with a value of $r=0.486(p<0.001)$.

\section{Multiple Hierarchical Regression Analysis}

In examining the moderating quality of self-esteem with regard to the relationship between cyberbullying victimization and cyberbullying perpetration, a hierarchical multiple regression was conducted. The dependent variable for the models is cyberbullying perpetration. Model 1 includes cyberbullying victimization as its independent variable, Model 2 includes self-esteem as its independent variable while Model 3 includes cyberbullying victimization as its independent variable with self-esteem as its interaction term. Table 2 below summarises the analysis.

According to model 1, cyberbullying victimization explains $24 \%$ of the variance in cyberbullying perpetration where $\left.\left(\mathrm{R}^{2}=.24\right), \mathrm{F}(1,118)=36.58, p<.001\right)$. This shows that cyberbullying victimization is able to predict cyberbullying perpetration by $24 \%$. For Model 2, the analysis shows that self-esteem explains $24.5 \%$ of the variance where $\left.\left(\mathrm{R}^{2}=.25\right), \mathrm{F}(1,117)=1.28, p>.05\right)$. Hence, there is insufficient proof to contend that self-esteem predicts cyberbullying perpetration. Model 3 shows that the inclusion of the interaction term within the model explains

\begin{tabular}{|c|c|c|c|c|}
\hline \multicolumn{3}{|l|}{ Model } & \multicolumn{2}{|r|}{ B } \\
\hline \multirow[t]{2}{*}{1} & \multicolumn{2}{|c|}{ (Constant) } & & 10.175 \\
\hline & \multicolumn{2}{|c|}{ (Victimization) } & & 1.154 \\
\hline \multirow[t]{2}{*}{2} & \multicolumn{2}{|c|}{ (Constant) } & & 10.175 \\
\hline & \multicolumn{2}{|c|}{ (Self-esteem) } & & -.215 \\
\hline \multirow[t]{4}{*}{3} & \multicolumn{3}{|c|}{ (Constant) } & 10.169 \\
\hline & \multicolumn{2}{|c|}{ (Victimization) } & & 1.151 \\
\hline & \multicolumn{2}{|c|}{ (Self-esteem) } & & -.267 \\
\hline & \multicolumn{2}{|c|}{ Interaction Term } & & -.300 \\
\hline \multicolumn{5}{|c|}{ Table 3: Beta Values Table } \\
\hline Model & $\mathrm{R}$ & $\mathrm{R}^{2}$ & $\mathrm{R}_{\text {change }}$ & $\mathrm{F}_{\text {change }}$ \\
\hline 1 & 0.49 & 0.24 & 0.24 & 36.58 \\
\hline 2 & 0.50 & 0.25 & 0.01 & 1.28 \\
\hline 3 & 0.51 & 0.26 & 0.01 & 1.75 \\
\hline
\end{tabular}
analysis. perpetration and victimization. This could be attributed to the nature of self-esteem where self-evaluation does not exist cyberbullying perpetration and self-esteem

an additional variance of $1 \%, \mathrm{R}_{\text {change }}^{2}=.01$. The $\mathrm{F}$ change is not statistically significant, $\mathrm{F}(1,116)=1.75, \mathrm{p}>.05)$. Hence, self-esteem does not act as a moderating factor for the relationship between cyberbullying victimization and perpetration. Figure 3 refers to the Beta values from the

According to model 1, victimization significantly predicts perpetration $($ Beta $=0.49, \mathrm{t}=6.05, \mathrm{p}<.001$ ). This supports hypothesis 1 , therefore, that: cyberbullying victims are likely to be cyberbullying perpetrators. According to model 2, self-esteem does not significantly predict perpetration as a model (Beta $=-0.09, \mathrm{t}=-1.13, \mathrm{p}>0.05)$. According to model 3, results indicate that only higher victimization predicts higher perpetration with inclusion of the interaction term $($ Beta $=0.49, \mathrm{t}=6.06, \mathrm{p}<.001)$. Also, according to model 3 , the interaction between victimization and self-esteem is significant (Beta $=-0.11, \mathrm{t}=-1.32, \mathrm{p}$ $>0.05$ ). This does not support hypothesis 2: self-esteem weakens the likelihood of people who are cyberbullying victims also being cyberbullying perpetrators.

\section{DISCUSSION}

This study aimed to examine the relationship between cyberbullying victimization and cyberbullying perpetration. Based on the analysis, cyberbullying victims are shown to tend to engage in cyberbullying perpetration, hence paralleling previous studies [15]-[17], [24]. This could be due to the negative experience of being bullied, creating a desire for revenge and compensation, which fuels the vicious cycle of cyberbullying [14]. Furthermore, the lack of consequences for cyberbullying as observed by the victim might be seen as an opportunity for perpetration in seeking revenge. Thus, further fuelling the vicious cycle of

cyberbullying. The link between cyberbullying and perpetration can also be attributed to the level of cognizance St $\Phi$. EfFopondents regatding the natpre and defingition of cyberbullying. The highly relative nature of cyberbullying where some acts might be perceived 56 ightly, unBeRnownst of 9 the perpetrator .486 manner in 6.04 gich other ingjviduals might receive such acts, whether hurtful or detrimental, due

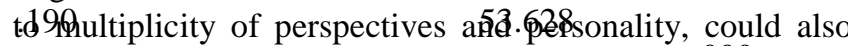
cloud individuals' judgment in unknowingly engdging in $\begin{array}{llll}\text { cyberbullying. } & -.091 & -1.130 & .261\end{array}$

189 In relation to the second finding, self-esteem was npt found to mediate cyberbully.jing victimization and pespetration which cpntradicts seyeral previous lititeratures whigh contend thats low self cyberbullying [18], [20] in addition to a study which relates high self-esteem levels with cyberbullying [22]. Therefore, the finding of this study only aligns with [21] where low levels of self-esteem do not predict cyberbullying

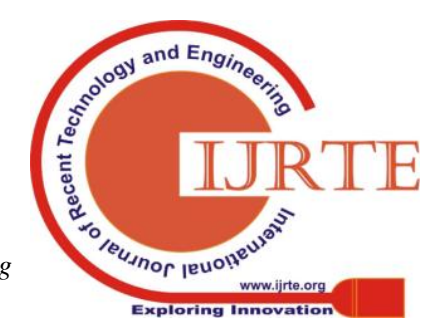


outside relations to other people hence disallowing individuals from disconnecting from that relationship. Therefore, boundaries are also established in the manner and way in which individuals treat others thus low levels of self-esteem is not predictive of cyberbullying perpetration and victimization.

The findings of this research has implications on the management of counseling programmes, case management and anti-bullying prevention programmes. Firstly, counselors should be mindful that the treatment should not focus solely on the behavior modification of the bully but on the healing process as these perpetrators might be the victims of bullying in the past. Secondly, case management of bullying cases should focus on developing empathetic skills towards victims rather than focusing on punishing perpetrators. Thirdly, conventional method in anti-bullying programmes should gear towards developing coping skills and self-assertive measures in victims. The findings may suggest that as part of anti-bullying prevention, the public should be educated on the psychological transformation from victimization to perpetration as to prevent victims from overcompensating lack of self-protection with aggression.

Several limitations were identified in this study. Firstly, data collection was conducted mainly in an environment which does not allow participants to fully immerse in the instrument which may influence the responses recorded. Future studies should utilise in-depth interviews and a more robust methodology to examine the topic thoroughly. Secondly, the sampling method used in this study may not lead to a finding capable of generalisation and with its restrictive nature may not be able to provide a more representative data of the population as the sample were mostly university students of a common financial and family background. Thirdly, the sample included in the study may also have been less representative given the large population.

\section{ACKNOWLEDGMENT}

The authors received financial support for the research and authorship of this article from Universiti Kebangsaan Malaysia Research Grant coded GUP-2017-079.

\section{REFERENCES}

[1] M. Wong-Lo and L. M. Bullock, "Digital Aggression: Cyberworld Meets School Bullies," Preventing School Failure: Alternative Education for Children and Youth, vol. 55, pp. 64-70, 2011/01/31 2011.

[2] Tan, K.H. Cyberbullying: A Cursory Review in Stop Cyberbullying. Bangi: UKM Press, 2018, pp. 17-34

[3] P. K. Smith, J. Mahdavi, M. Carvalho, S. Fisher, S. Russell, and N. Tippett, "Cyberbullying: its nature and impact in secondary school pupils," Journal of Child Psychology and Psychiatry, vol. 49, pp. 376-385, 2008..

[4] J. Raskauskas, "Text-bullying: associations with traditional bullying and depression among New Zealand adolescents," Journal of School Violence, vol. 9, pp. 74-97, 2010.
[5] J. Snakenborg, R. A. Gable, and R. V. Acker, "Cyberbullying: prevention and intervention to protect our children and youth," Preventing School Failure, vol. 55, pp. 88-95, 2011.

[6] J. Raskauskas and A. D. Stoltz, "Involvement in traditional and electronic bullying among adolescents," Development Psychology, vol. 43, pp. 564-575, 2007.

[7] R. S. Tokunaga, "Following you home from school: a critical review and synthesis of research on cyberbullying victimization," Computers in Human Behaviour, vol. 26, pp. 277-287, 2010.

[8] D. Nikolaou, "Does cyberbullying impact youth suicidal behavious?," Journal of Health Economics, vol. 56, pp. 30-46, 2017.

[9] G. W. Wendt, M. Appel-Silva, Y. Kovas, and T. Bloniewski, "Links between cyberbullying, depression and self-esteem in a sample of Brazilian adolescents," The European Proceedings of Social \& Behavioural Sciences, vol. 49, pp. 782-793, 2018.

[10] G. Gini and T. Pozzoli, "Association between bullying and psychosomatic problems: a meta-analysis," Pediatrics, vol. 123, pp. 1059-1065, 2009.

[11] S. Pabian, H. Vandebosch, K. Poels, V. V. Cleemput, and S. Bastiaensens, "Exposure to cyberbullying as a bystander: an investigation of desensitizattion effects among early adolescents," Computers in Human Behaviour, vol. 62, pp. 480-487, 2016.

[12] H. Vandebosch and K. V. Cleemput, "Defining cyberbullying: a qualitative research into the perceptions of youngsters," Cyberpsychology \& Behaviour, vol. 11, pp. 499-503, 2008.

[13] S. Hinduja and J. W. Patchin, Bullying beyond the School Yard. California: Corwin Press, 2008.

[14] K. Varjas, J. Talley, J. Meyers, L. Parris, and H. Cutts, "High school students' perceptions of motivations for cyberbullying: an exploratory study," West J Emerg Med, vol. 11, pp. 269-273, 2010.

[15] M. Walrave and W. Heirman, "Cyberbullying: predicting victimization and perpetration," Children and Society, vol. 25, pp. 59-72, 2010.

[16] S. A. Hemphill and J. A. Heerde, "Adolescent predictors of young adult cyberbullying perpetration and victimization among Australian youth," Journal of Adolescent Health, vol. 55, pp. 580587, 2014.

[17] E. Rice, R. Petering, H. Rhoades, H. Winetrobe, J. Goldbach, A. Plant, et al., "Cyberbullying perpetration and victimization among middle-school students," American Journal of Public Health, vol. 105, pp. 66-72, 2015.

[18] J. W. Patchin and S. Hinduja, "Cyberbullying and self-esteem," Journal of School Health, vol. 80, pp. 614-621, 2010.

[19] G. Brewer and J. Kerslake, "Cyberbullying, self-esteem, empathy and loneliness," Computers in Human Behaviour, vol. 48, pp. 255 260, 2015.

[20] K. A. Fanti and C. C. Henrich, "Effects of self-esteem and narcissism on bullying and victimization during early adolescence," Journal of Early Adolescence, vol. 35, pp. 5-29, 2014.

[21] C. A. Rose, C. D. Slaten, and J. L. Preast, "Bully perpetration and self-esteem: examining the relation over time," Behavioural Disorders, vol. 42, pp. 159-169, 2017.

[22] B. Choi and S. Park, "Who becomes a bullying perpetrator after the experience of bullying victimization? the moderating role of self-esteem," Journal of Youth and Adolescence, vol. 47, pp. 24142423, 2018.

[23] M. Rosenberg, Society and the Adolescent Self-Image. Princeton, NJ: Princeton University Press, 1965.

[24] M. Ybarra and K. Mitchell, "Online aggressor-targets, aggressors, and targets: a comparison of associated youth characteristics,' Journal of Child Psychology and Psychiatry, vol. 45, pp. 13081316. 


\section{AUTHORS PROFILE}

Tan Kim Hua TAN, Kim Hua (Ph.D) is Assoc

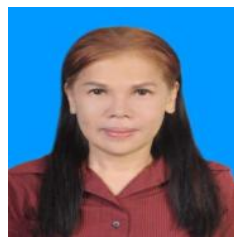

Professor of Applied Linguistics at the Centre of Literacy and Socio Cultural Transformation, Faculty of Social Sciences and Humanities, Universiti Kebangsaan Malaysia. Her research interests are in digital humanities, including corpus-driven research, corpus lexicography and the interrelationship between language, power and ideology. Her most recent paper in 2019 "The "Geopolitical" Factor in the Syrian Civil War: A Corpus-Based Thematic Analysis' is published in Sage Open.

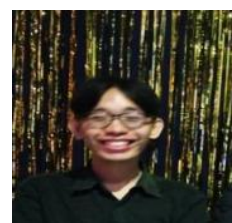

Nicholas Sia Heng Hwa Nicholas Sia Cheng Hwa is a freelance writer for hire, doing TV scriptwriting, writing for various sites as well as proofreading and editing. He graduated from HELP University with a Bachelor's in Psychology (Hons) in 2017. In his free covers from others. time, he plays music, both his own material and

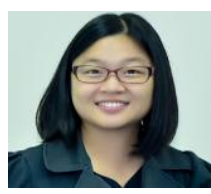

Sheau Tsuey Chong received her doctorate from Swinburne University of Technology, Australia in 2010 (youth development). Her recent publication focus on at rish youth and social capital. She is a research fellow at Centre for Youth Empowerment at the National University of Malaysia. She is also a senior lecturer of Psychology Program at the same university. She is a member of the National Counselor board and Malaysian Psychological Association. 